\title{
SPH-based numerical modeling for the post-failure behavior of the landslides triggered by the 2016 Kumamoto earthquake
}

\author{
Zili Dai ${ }^{1,3^{*}}$, Fawu Wang ${ }^{1}$, Yu Huang ${ }^{2}$, Kun Song ${ }^{3}$ and Akinori lio ${ }^{1}$
}

\begin{abstract}
Background: The 2016 Kumamoto earthquake triggered many fast landslides in Kyushu Region, Japan, which caused great damages and increased difficulty of rescue after the earthquake. The post-failure behavior analysis of the earthquake-triggered landslides is of great importance to determine the hazardous areas and estimate the extent of damage.

Results: The features of the landslides triggered by the Kumamoto earthquake were presented and the damages caused were described based on the field investigation. Then, a mesh-free particle method called smoothed particle hydrodynamics (SPH) was introduced and a 3D numerical model was established based on a Bingham flow model and the equations of continuity and motion. Applying this model, two typical fast landslides in the Kumamoto earthquake zone were simulated. Their propagations were reproduced and the time histories of the velocity and run-out distance were obtained.

Conclusions: The run-out distances simulated matched the in-situ evidences, thus verifying the calculation accuracy of the SPH model. The SPH-based approach presented in this work for the post-failure behavior analysis should contribute to the prevention and mitigation of fast landslide disaster.
\end{abstract}

Keywords: Fast landslides, Post-failure behavior, Kumamoto earthquake, Smoothed particle hydrodynamics, Numerical simulation

\section{Background}

At AM 01:25 on 16 April 2016 (local time), a strong earthquake occurred in Kumamoto City in Kyushu Region, Japan. The epicenter was located at $32.782^{\circ} \mathrm{N}$, $130.726^{\circ} \mathrm{E}$ (GPS coordinates), with a focal depth of about $10 \mathrm{~km}$. According to the Japan Meteorological Agency, the magnitude of the main shock in Kumamoto earthquake was $\mathrm{M}_{\mathrm{S}} 7.3$ ( $\mathrm{Mw} 7.0$ according to the US Geological Survey). About 28 h before the main shock, a foreshock earthquake with a magnitude 6.2 had shook the same region severely at 21:26 JST on April 14 .

\footnotetext{
* Correspondence: zili.dai@riko.shimane-u.ac.jp

'Department of Geoscience, Shimane University, Matsue, Shimane 690-8504, Japan

${ }^{3}$ Hubei Key Laboratory of Disaster Prevention and Reduction, China Three Gorges University, Yichang 443002, China

Full list of author information is available at the end of the article
}

According to Okumura (2016), this series of earthquake shocks were triggered by the reactivation of the Futagawa and Hinagu Faults. Figure 1 shows the location of the earthquake shocks and fault zones in the earthquake region, which exactly proves Okumura's idea.

During the earthquake, the strongest ground motion recorded in Mashiki Town was about $1.18 \mathrm{~g}$. The intense ground shaking directly damaged numerous houses, roads and bridges, resulting in at least 49 deaths and forcing 90,000 people to evacuate from their homes. Besides, a large number of landslides were triggered by the earthquake. Figure 2 shows the landslide distribution near the Aso Bridge after the earthquake. Under seismic actions, the earthquake-triggered landslides commonly are characterized by high velocity and long run-out (Wang et al. 2009; Yin et al. 2009). The great mobility 


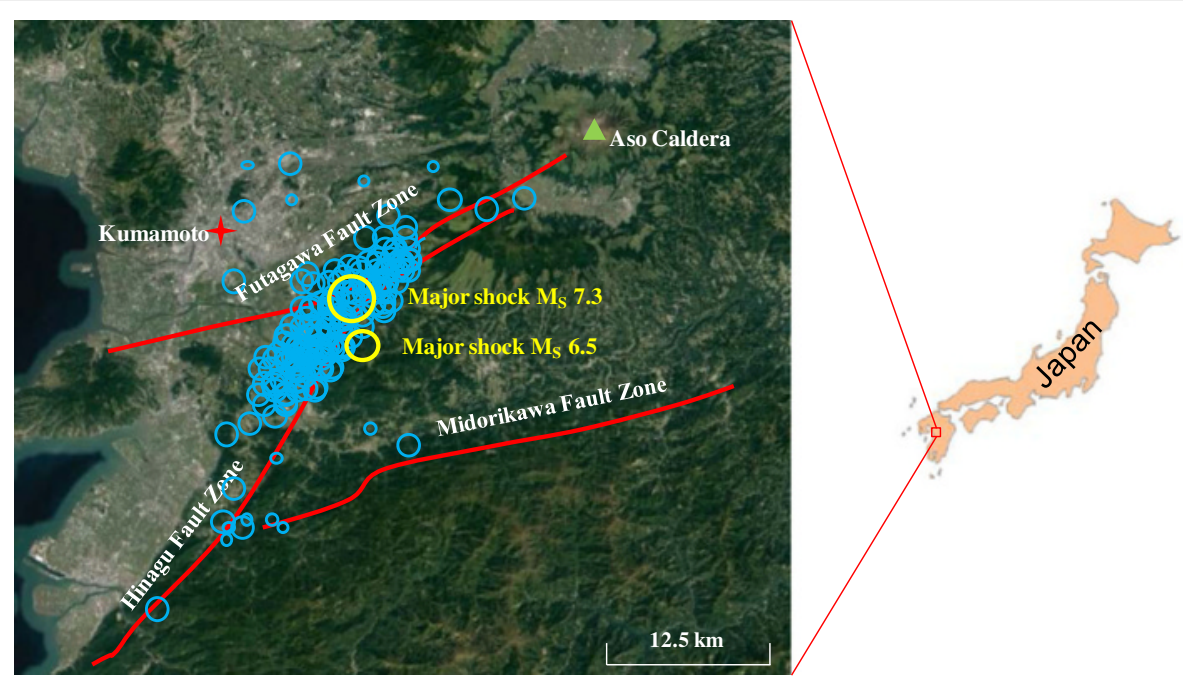

Fig. 1 Aerial view of the region indicating the location of the earthquake shocks and fault zones (Base map is from Google earth)

can produce extensive damage to human lives and engineering structures. As shown in Fig. 3, many houses were pushed down by the fast moving landslide mass, a lot of roads were cut, and numerous underground pipelines and water supply network were damaged during the Kumamoto earthquake. Therefore, the fast landslides triggered by the earthquake have huge destructive power which could easily destroy facilities and structures, and immensely increase the difficulty of rescue and reconstruction after the earthquake. The prediction and mitigation of earthquake-triggered landslides is one of the most significant problems facing our society today.

As always, analytical investigation of landslide stability through limit equilibrium method (LEM) and finite element method (FEM) is a hot topic in geology engineering and many promising results have been obtained (Collins and Sitar, 2011; Zhou and Cheng, 2013; Xu et al., 2013). However, for earthquake-triggered landslides,

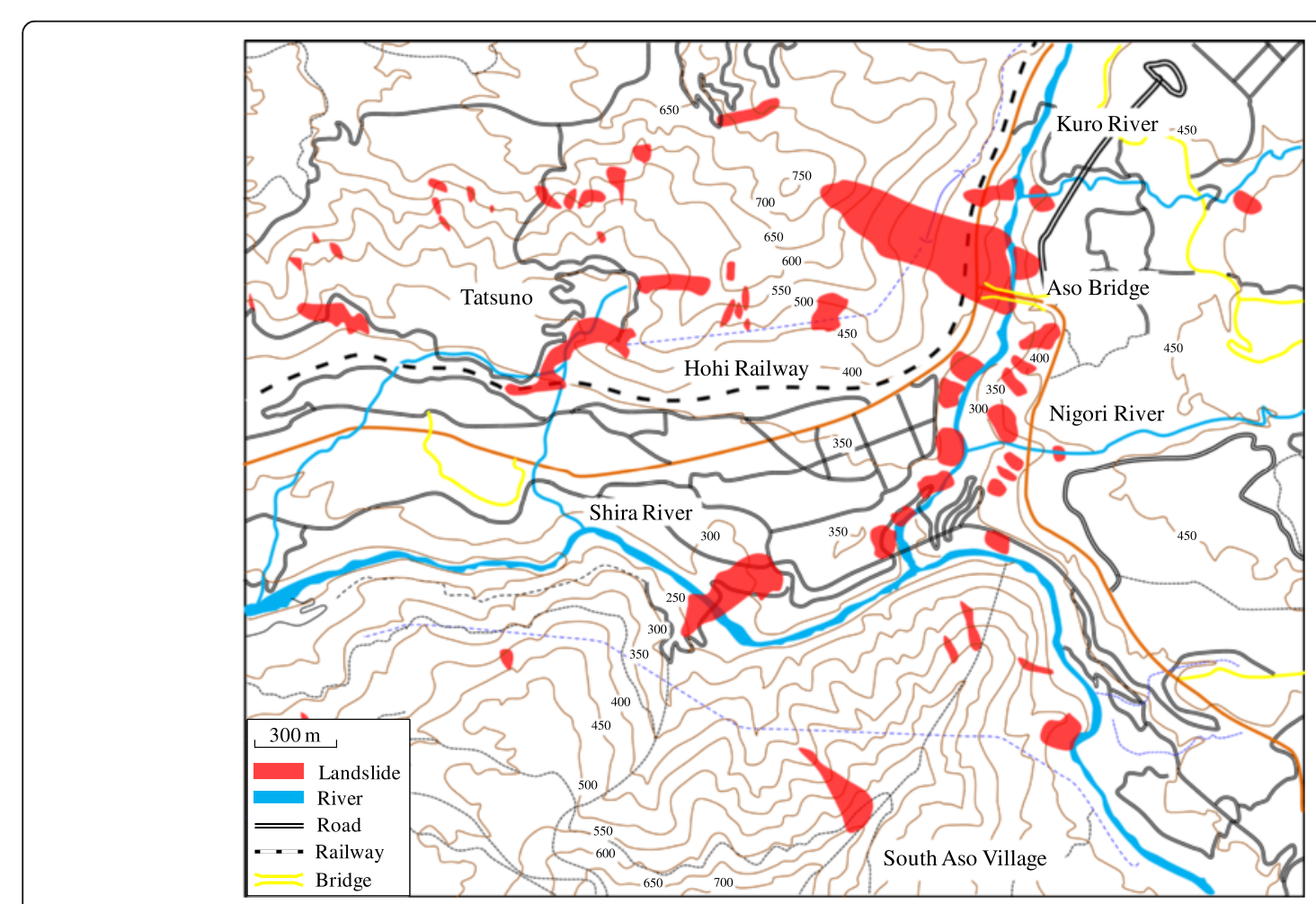

Fig. 2 Landslide distribution near the Aso Bridge after the earthquake (Base map is from Geospatial Information Authority of Japan) 

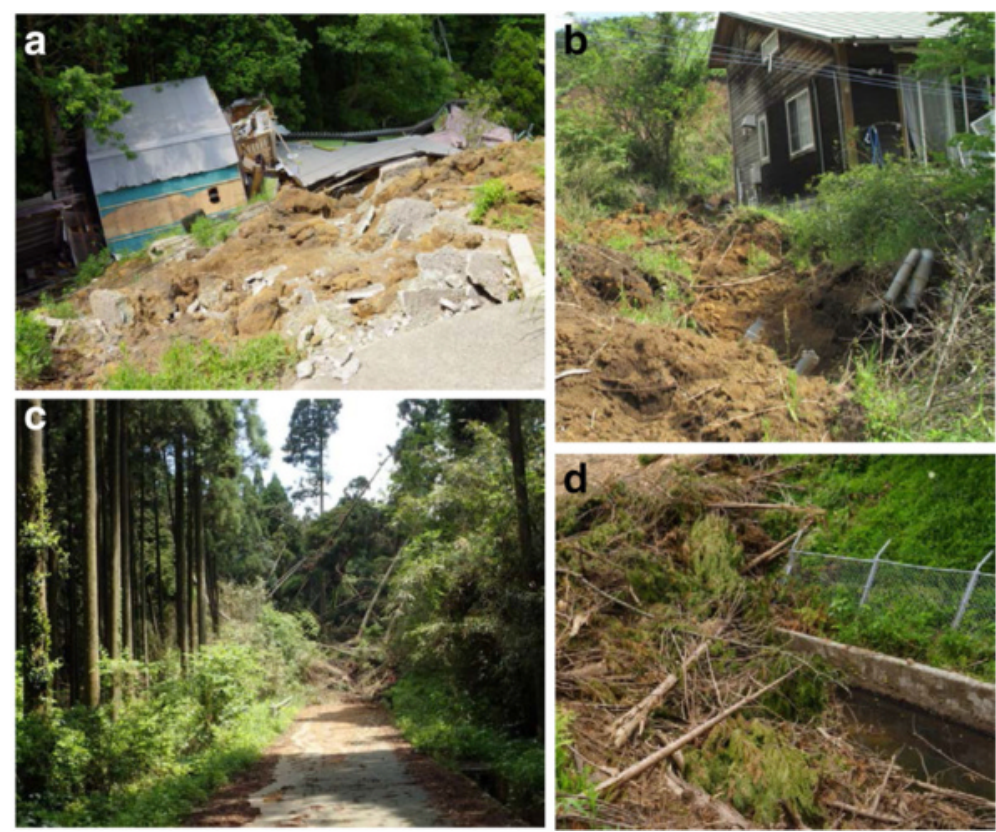

Fig. 3 Damages caused by earthquake-triggered landslides in Kumamoto; a collapsed houses, b broken underground pipelines, c road destroyed by the landslide mass, $\mathbf{d}$ damaged water channel

the destructive potential often cannot, in practice, be reduced by stabilization of the source areas. To minimize the degree of destruction, not only the timely forecast of a potential landslide is of great significance, but also the reasonable estimation of its post-failure behavior and consequences. The information regarding the evolution processes, the velocity distribution, as well as the possible hazard zone can be valuable for determining the hazardous areas, estimating the intensity of the hazard and setting up appropriate protection measures in practical engineering.

For run-out prediction, empirical formulations (derived from a large sample of landslides statistical data) and analytical approaches (i.e. simple sliding block models) indeed provide valuable information. They are usually of high approximation and disregard crucial local topography effects such as diversions or bifurcations. To better predict the consequence of landslides, a robust computational tool that can capture the whole process would offer additional information of significance. For instance, Andersen and Andersen (2010) presented a numerical model based on the material point method (MPM) to simulate the dynamic evolution of landslides; Zhang et al. (2015a) adopted discontinuous deformation analysis (DDA) to study the run-out distance of landslides induced by the 2008 Wenchuan earthquake; Zhang et al. (2015b) simulated a landslide process occurred in Southern China by the particle finite element method (PFEM). Discrete element method (DEM) is a possible approach to simulate soil flow or landslides. For example, Lin and Lin (2015) investigated the evolution of a large landslide in the Butangbunasi River, southern Taiwan using the DEM. This method treats the geomaterial as an assembly of rigid grains that are governed by the Newton's laws of motion. Nevertheless, the utilization of the DEM in practice is restricted due to its undesirable nature of simulating individual soil grains. To reduce the computation, the number of grains used in typical DEM simulations is usually much less than that in real problems.

In the field of CFD, smoothed particle hydrodynamics $(\mathrm{SPH})$ is a recently developed mesh-free particle method. The main advantage of this method is that it bypasses the need for a numerical grid and avoids the severe mesh distortions caused by large deformation. In contrast to the DEM, SPH predicts material behavior on the basis of the classical conservation equations of mass, momentum and energy, so that it is more suitable for landslide modeling. Recently, several preliminary applications of $\mathrm{SPH}$ to landslides have been undertaken with some promising results. For example, McDougall and Hungr (2004) developed an SPH model combined with depth-integrated equations to simulate the propagation stage of flow-like landslides. This model was then extended by Pastor et al. (2008; 2009; 2014), Haddad et al. (2010) and Cascini et al. (2014) to simulate the dynamic process of flowlike landslides, debris flows, lahars and avalanches. These models have many unique features, such as the 
ability to account for bed entrainment, rheology variation, nonhydrostatic and anisotropic internal stress states. Huang et al. $(2011 ; 2012)$ presented an SPH model combined with Navier-Stokes equations to predict the run-out distance of the flow-like landslides triggered by the 2008 Wenchuan earthquake. This model was then extended to 3D by Dai et al. (2014). In this paper, the 3D SPH model is introduced to simulate the propagation of two typical landslides induced by the 2016 Kumamoto earthquake. Combining with the field investigation, the post-failure behavior of the landslides is analyzed and the performance of the SPH model is evaluated. The sliding path, run-out distance, velocities, and the distribution deposits obtained in the simulation could play important roles in mapping hazardous areas and estimating hazard intensity, and also the identification and design of appropriate protective measures.

\section{Methods}

\section{Concepts of smoothed particle hydrodynamics}

$\mathrm{SPH}$ is a mesh-free particle method based on a pure Lagrangian description which was first developed to solve astrophysical problems in three-dimensional open space (Lucy, 1977; Gingold and Monaghan, 1977). The basic concept of this method is shown in Fig. 4. The domain is represented by a finite number of particles. The field variables of those particles are estimated by summing the contributions from the neighboring particles within a certain horizon:

$$
\begin{aligned}
& \left\langle f\left(x_{i}\right)\right\rangle=\sum_{j \in H_{i}} \frac{m_{j}}{\rho_{j}} f\left(x_{j}\right) W_{i j} \\
& \left\langle\nabla \cdot f\left(x_{i}\right)\right\rangle=\sum_{j \in H_{i}} \frac{m_{j}}{\rho_{j}} f\left(x_{j}\right) \nabla_{i} W_{i j}
\end{aligned}
$$

where, the angle brackets $<>$ denote a particle approximation, $x_{i}$ represents the concerning particle, and $x_{j}$ is a neighboring particle in the support area; $m$ and $\rho$ are the mass and density of the particle, $W$ is a kernel function. A cubic B-spline function, originally used by Monaghan and Lattanzio (1985), is employed as the kernel function in this paper.

\section{Neighboring particle searching algorithm}

$\mathrm{SPH}$ is a mesh-free method based on interactions with the neighboring particles. The creation of the neighbor list is one of the key points in terms of the high performance of the code. And the efficiency of the SPH model depends highly on how to build and use the neighbor list, especially in the 3D model. The Verlet neighbor list algorithm (Verlet, 1967), as one of the most efficient neighboring particle searching methods, was adopted in the presented model. First, the distance between each particle pair was calculated, then a potential neighbor list was constructed in which the particle pair distances were all within a "skin" layer radius, $r_{s}$. In this list, only those pairs of particles within a distance cutoff radius, $r_{c}$, will interact, resulting in a further neighbor list. Note that the neighbor list is updated every time step while the potential neighbor list is updated every $N$ time steps. The value of $N$ was suggested to be taken as 7, $r_{c}$ and $r_{s}$ can be taken as $2.5 r$ and $3.2 r$ respectively, where $r$ is the radius of the interacting particles (Verlet, 1967; Dominguez et al., 2011).

\section{Governing equations}

In this research, the equations of continuity and motion were used as governing equations:

$$
\begin{aligned}
& \frac{d \rho}{d t}=-\rho \frac{\partial \mathbf{v}^{\beta}}{\partial \mathbf{x}^{\beta}} \\
& \frac{d \mathbf{v}^{\alpha}}{d t}=\frac{1}{\rho} \frac{\partial \sigma^{\alpha \beta}}{\partial \mathbf{x}^{\beta}}+\mathbf{F}
\end{aligned}
$$

where $\rho$ is the density, $t$ is time, $v$ represents the velocity vector, the superscripts $\alpha$ and $\beta$ denote the coordinate directions, $\sigma$ is the stress tensor, $F$ is the external force vector per unit mass.

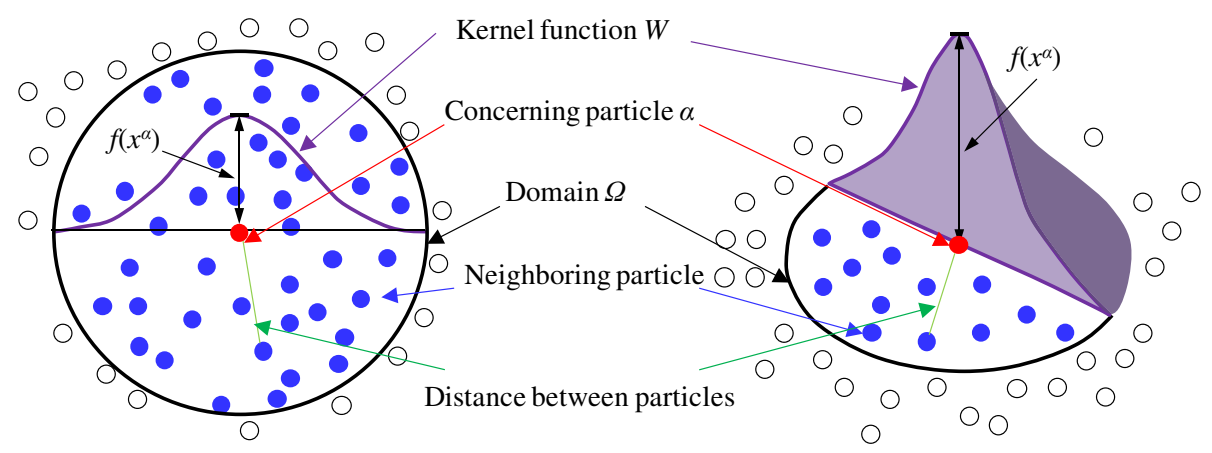

Fig. 4 The concept of Smoothed Particle Hydrodynamics 
According to Eq. (1), the SPH versions of the governing equations can be expressed as:

$$
\begin{aligned}
& \frac{d \rho_{i}}{d t}=\sum_{j=1}^{N} m_{j}\left(v_{i}^{\beta}-v_{j}^{\beta}\right) \frac{\partial W_{i j}}{\partial x_{i}^{\beta}} \\
& \frac{d v_{i}^{\alpha}}{d t}=\sum_{j=1}^{N} m_{j}\left[\frac{\sigma_{i}^{\alpha \beta}}{\left(\rho_{i}\right)^{2}}+\frac{\sigma_{j}^{\alpha \beta}}{\left(\rho_{j}\right)^{2}}\right] \frac{\partial W_{i j}}{\partial x_{j}^{\beta}}+F_{i}
\end{aligned}
$$

To avoids numerical oscillation and enhance the stability of the model, an additional artificial viscosity, $\Pi_{i j}$, was incorporated into the pressure terms of the equation of motion (Monaghan and Gingold 1983). Therefore, the Eq. (6) can be rewritten as:

$$
\frac{d v_{i}^{\alpha}}{d t}=\sum_{j=1}^{N} m_{j}\left[\frac{\sigma_{i}^{\alpha \beta}}{\left(\rho_{i}\right)^{2}}+\frac{\sigma_{j}^{\alpha \beta}}{\left(\rho_{j}\right)^{2}}+\prod_{i j}\right] \frac{\partial W_{i j}}{\partial x_{j}^{\beta}}+F_{i}
$$

\section{Constitutive model}

The selection of suitable constitutive models is very important in numerical simulations. Traditional soil constitutive relationships, such as the Duncan-Chang model, the Drucker-Prager model and the Cam-Clay model, have all been widely used in previous studies, with many promising results. However, these conventional models are framed in terms of solid mechanics and are only suitable for describing the constitutive behavior over a certain range of strain. They are invalid for complicated problems associated with extremely large deformation such as earthquake-triggered landslides, in which the strain rate is far more than $100 \%$. In this type of situation, large deformation results in negligible stiffness in the soil materials, which will behave as a fluid. Therefore, constitutive models based on solid mechanics are not suitable to describe a earthquake-triggered flow-like landslide. Recently, a non-Newtonian fluid flow called the Bingham flow model has been widely applied to describe the fast landslide movement (Chen and Lee, 2002; Hassani et al., 2005; Ulusay et al., 2007; Blanc et al. 2011). In this work, therefore, the Bingham flow model was introduced as the constitutive model to describe the post-failure behavior of the fast landslides induced by the earthquake. For a Bingham fluid, the relationship between the shear strain rate and shear stress is given by:

$$
\tau=\left(\eta+\frac{\tau_{y}}{\left(D_{\Pi}\right)^{1 / 2}}\right) D
$$

where, $\tau$ is the shear stress, $\tau_{y}$ is the yield shear stress, $\eta$ represents the viscosity coefficient. $D$ donates the tensor of strain-rates which can be defined by:

$$
D_{i j}=\frac{1}{2}\left(\frac{\partial v_{i}}{\partial x_{j}}+\frac{\partial v_{j}}{\partial x_{i}}\right)
$$

$D_{\Pi}$ is the second invariant of the tensor of strain-rates, and can be defined by:

$$
D_{\prod}=\frac{1}{2} D_{i j} D_{i j}
$$

\section{Boundary treatment}

During the propagation, landslide mass receives contact forces from the local topography. In response to the repulsive force, the landslide may change direction, spread or contract, and split or join in while traveling across the $3 \mathrm{D}$ terrain. To truly represent the propagation of the

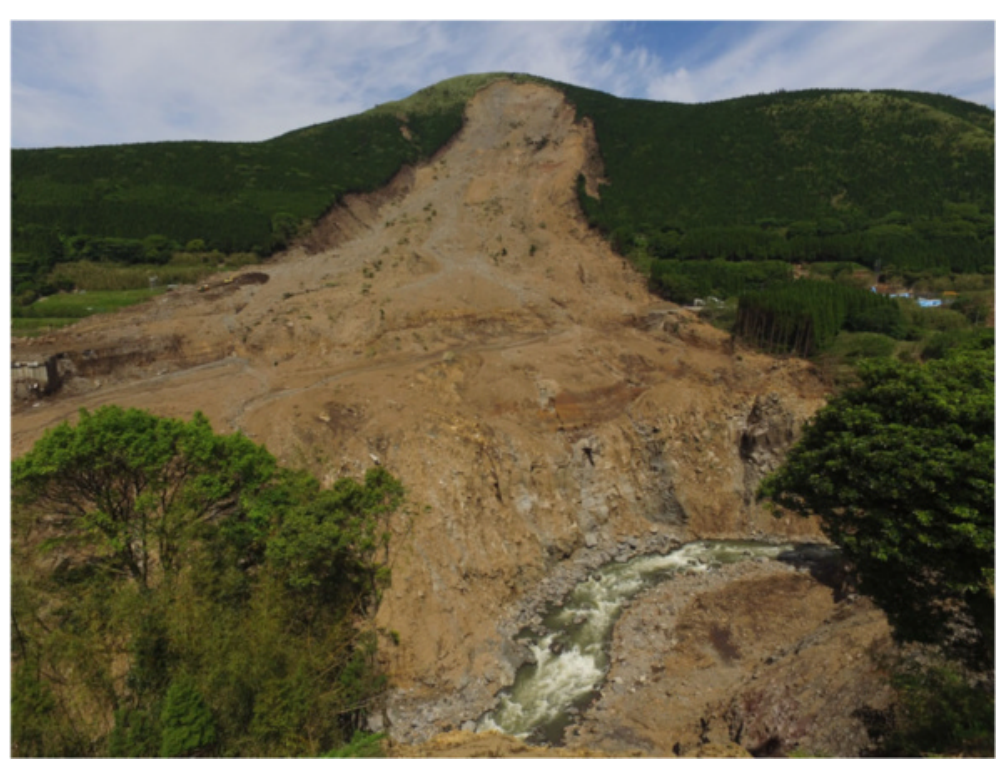

Fig. 5 The front view of Aso Bridge landslide 


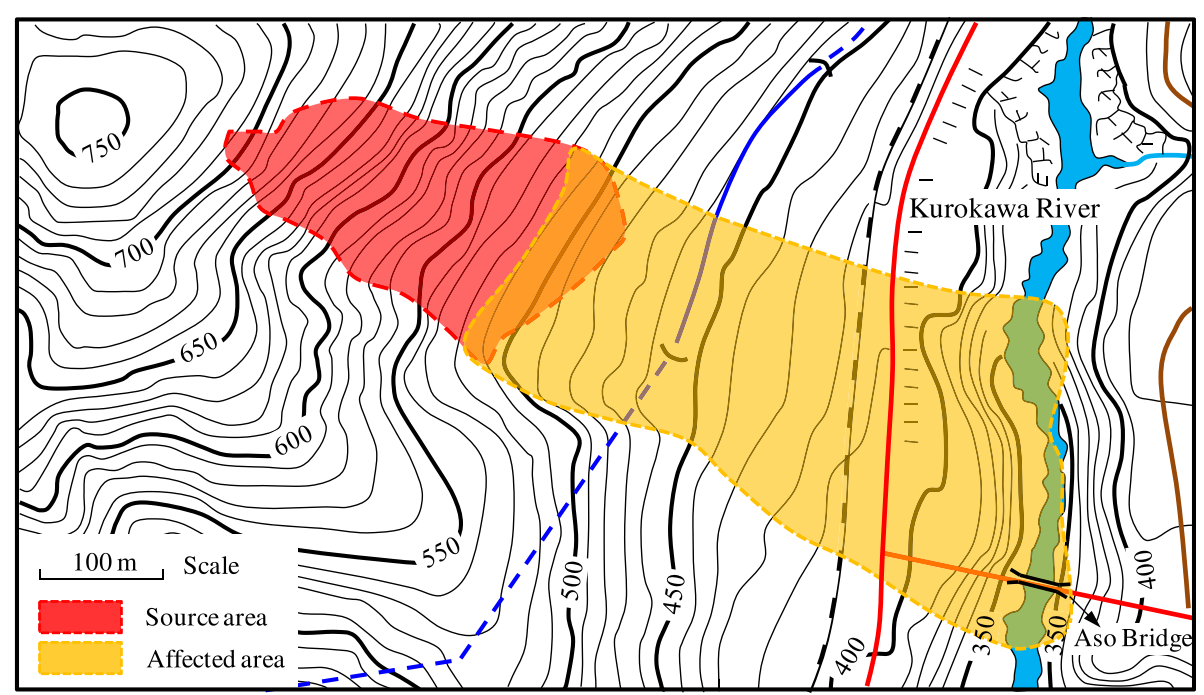

Fig. 6 The contour map of the landslide near the Aso Bridge (Base map is from Geospatial Information Authority of Japan)

landslide, it is therefore important to accurately consider the effect of the solid boundary on the slope movement. No-slip boundary condition is a widely used boundary treatment method when dealing with free surface flows (Monaghan, 1994; Morris et al., 1997). The performance of this boundary treatment has been validated by previous works (Lo and Shao, 2002; Dai et al., 2014). Therefore, the presented work incorporates a no-slip boundary condition to consider the contact forces from the local topography.

\section{Results and discussions}

As shown in Fig. 2, a lot of landslides were triggered by the 2016 Kumamoto earthquake. In this section, two typical landslides were taken as the case studies to analyze their post-failure behavior. One is the landslide near the Aso Bridge and anther one is located in the northeast of the Aso Volcanological Laboratory of Kyoto University.

\section{The landslide near the Aso Bridge}

Figure 5 is a front view of the landslide at $32.885^{\circ} \mathrm{N}$, $130.987^{\circ} \mathrm{E}$ (GPS coordinates), on the bank of Kurokawa River in the village of Minami-Aso, Kumamoto Prefecture. This landslide was induced by the main shock occurred at 01:25 am (local time) on 16 April 2016. Figure 6 is the contour map of the landslide. The red area in the map represents the source area of the

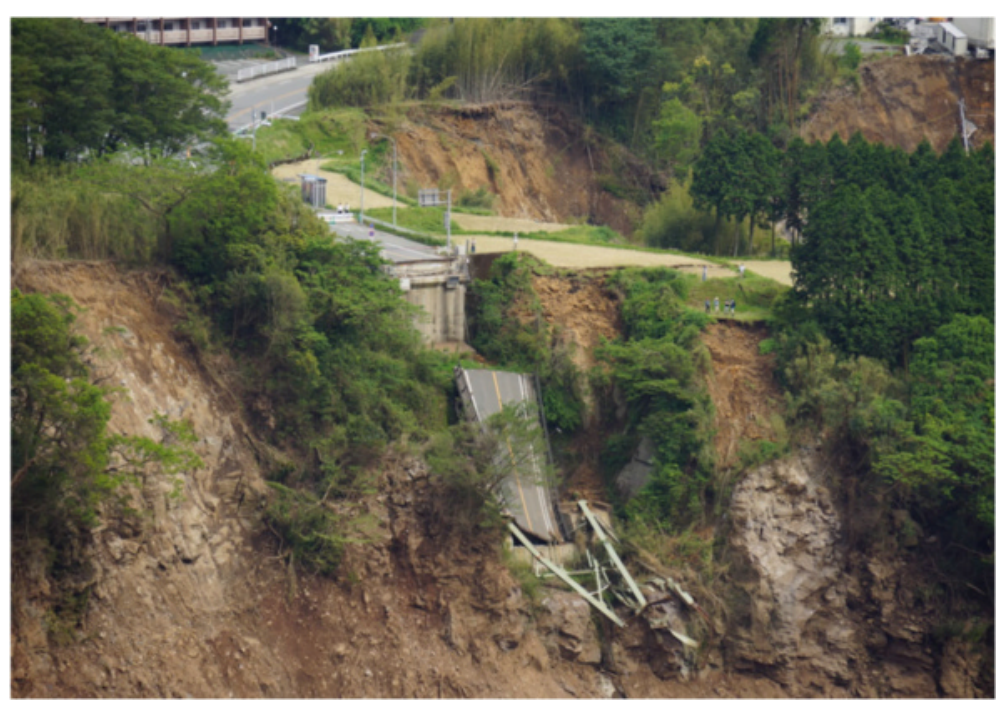

Fig. 7 The Aso Bridge tumbled into the Kurokawa River after the landslide event 


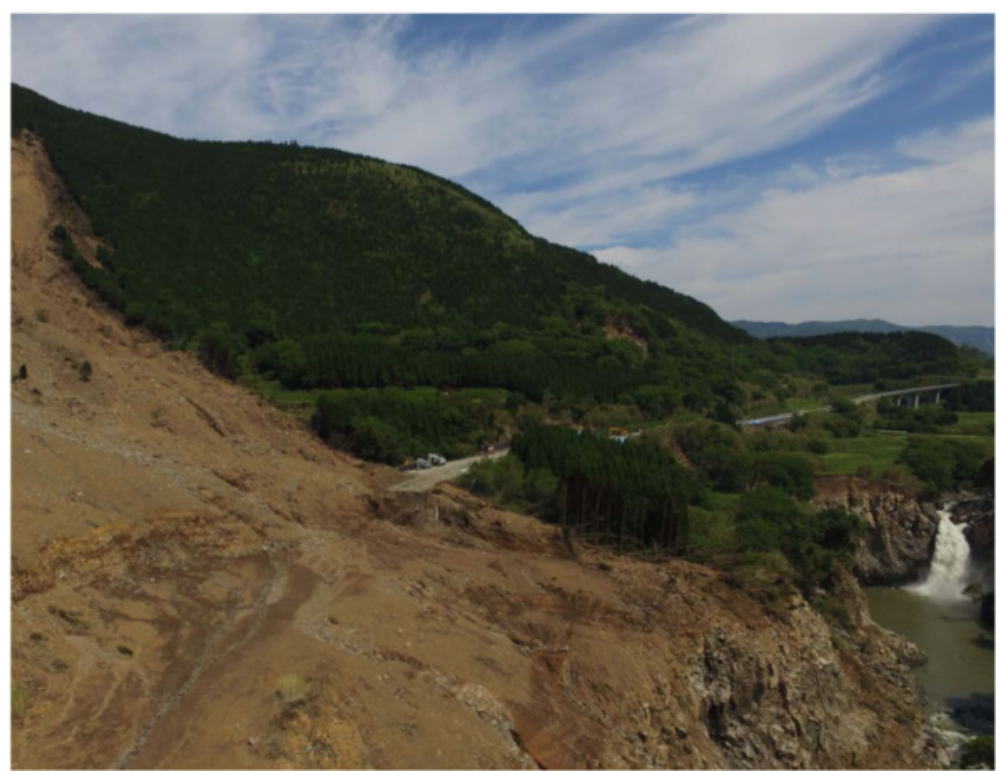

Fig. 8 The road buried by the displaced mass

landslide and the orange area donates the zone affected by the landslide. The run-out distance of this landslide was about $395 \mathrm{~m}$ and its slide direction was $\mathrm{S} 61.0^{\circ} \mathrm{E}$. The source area of the landslide was steep, about $38.6^{\circ}$. The elevation difference between the landslide toe and top was about $235 \mathrm{~m}$.

After failure, the landslide mass rushed down along the steep slope and completely destroyed the Aso Bridge, a long arch bridge spanning a deep gorge. This bridge was established in 1971 at the western tip of the Aso Volcano. Figure 7 shows the Aso Bridge after the landslide event, which tumbled into the Kurokawa River. As indicated in Fig. 6, a local railway and a road were located at the foot of the slope. They were both buried by the landslide mass, as shown in Fig. 8. Besides, a water supply channel on the slope was destroyed. Therefore, this landslide cut off the crucial lines of transportation and damaged the public facilities, which increasing the difficulty of rescue and reconstruction after the earthquake to a great degree.

This area is characterized by active volcano and soft ground composed of volcanic cohesive soil. As shown in Fig. 9, the volcanic cohesive soil are problematic because

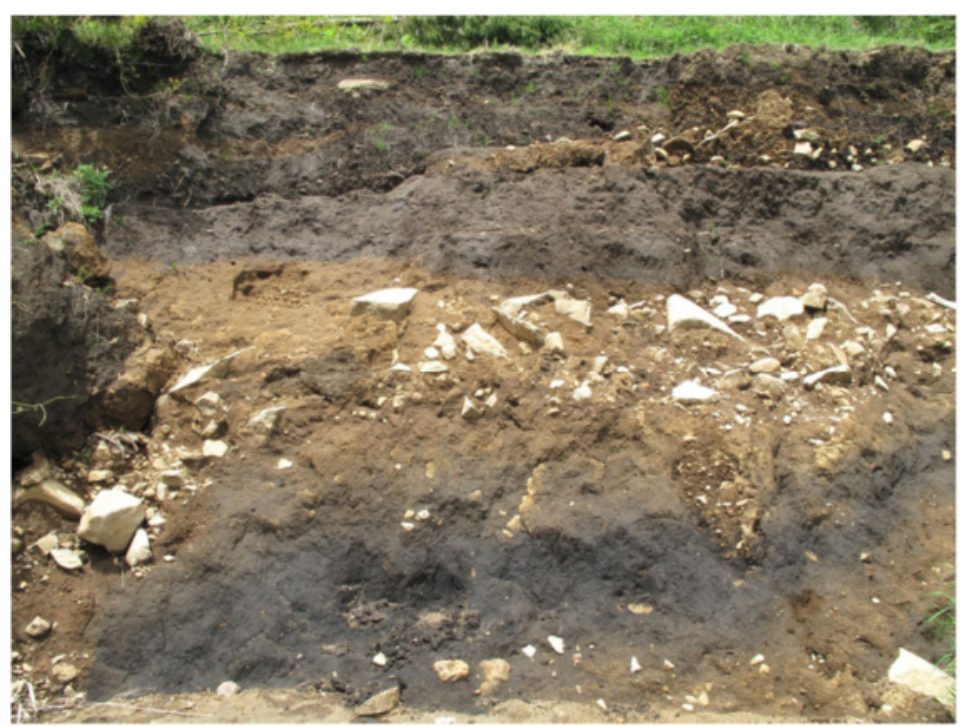

Fig. 9 Soft volcanic ash soil with gravel around the Aso Bridge landslide 


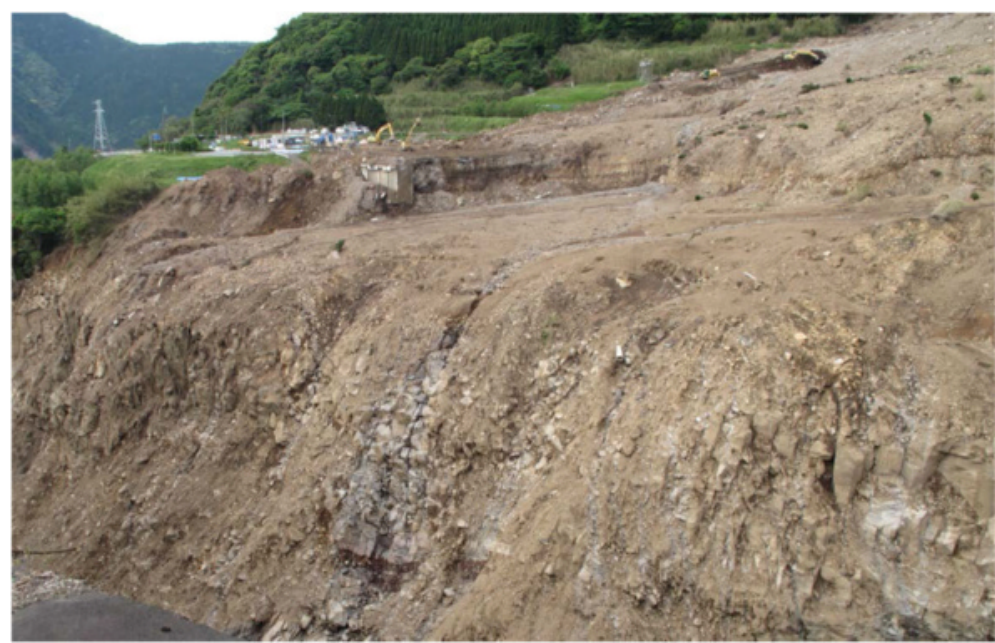

Fig. 10 Highly weathered bedrock at the foot of the Aso Bridge landslide

they are softened by disturbance due to their high water content and amorphous clay minerals (Hayashi et al., 2005). At the foot of the slope, the bedrock is highly weathered (see Fig. 10), which reduces the strength and stability of the rock mass. Therefore, the geologic condition in this area is comparatively poor.

To reproduce the landslide propagation, 3D numerical simulation was conducted using the SPH model. The landslide mass, Aso Bridge and boundary were discretized into a series of SPH particles with a diameter of $7 \mathrm{~m}$. The representative volume of each particle is the third power of the diameter, $343 \mathrm{~m}^{3}$ in this case. The landslide particles were evenly spaced with an initial velocity of $0 \mathrm{~m} / \mathrm{s}$ in the source area. The number of particles along depth is dependent on the depth of the sliding surface, and varies in different position. Note that the source area, the depth of the sliding surface, and the volume of the landslide mass could be estimated according to the topographical maps before and after the earthquake. The earthquake shake is one of the key factors influencing the initiation of landslides. However, this work aims to analyze the post-failure of the landslide mass. During the propagation of the landslides, it is difficult to make sure whether the earthquake shake still continues or not. Therefore, to simplify the calculation, the ground motion due to the earthquake was not included in the simulation of the landslide propagation.

The resulting numerical model is shown in Fig. 11a. There are 17,994 SPH particles in total, 1617 red particles for the landslide mass, 80 blue particles for the Aso Bridge and 16,297 white particles for the boundary. In SPH model, the material is represented by a series of arbitrarily distributed particles carrying field variables. Therefore, the calculation accuracy of the presented model depends on the number of the particles. With the increase of the SPH particles, more local information at the material point could be reflected. However, as a mesh-free method, SPH is relatively time-consuming compared with mesh-based methods. The computing time is nearly in proportion to the square of the particle number. When both of the accuracy and efficiency were considered together, 17,994 SPH particles with the diameter of $7 \mathrm{~m}$ were used in this case study. The parameters used in the simulation are shown in Table 1. Bingham fluid model was widely used in the SPH simulation of landslide propagation (Pastor et al., 2008; Huang et al., 2011; Cascini et al., 2014; Dai et al., 2014). In this model, the rheological parameter, yield strength and viscosity, can affect the numerical results to some extent. To calibrate the parameters of the Bingham model, a sensitivity analysis was performed by Haddad et al. (2010) to evaluate their effect on the post-failure behavior. The results shows that viscosity strongly influences flow velocity, and yield strength affects mainly the run-out distance and the final portion of the path where the slope is moderated. In this study, the yield strength of the soil material was estimated based on the results of the standard penetration tests in the field work. Viscosity was difficult to obtain through in-site tests. Remaitre (2006) measured the viscosity of debris flows in the laboratory through parallel-plates rheometrical tests and inclinedplane tests; the viscosity is 100 to $200 \mathrm{~Pa} \cdot \mathrm{s}$. Haddad et al. (2010) used 50 to $500 \mathrm{~Pa} \cdot \mathrm{s}$ to calculate the run-out distance of a lahar. According the above researches, $100 \mathrm{~Pa} \cdot \mathrm{s}$ was used as the viscosity of the landslide mass in this work.

Figure 11 presents the simulated sliding process of the landslide. The soil mass slid down along the steep slope and rushed towards the deep gorge at the foot of the 


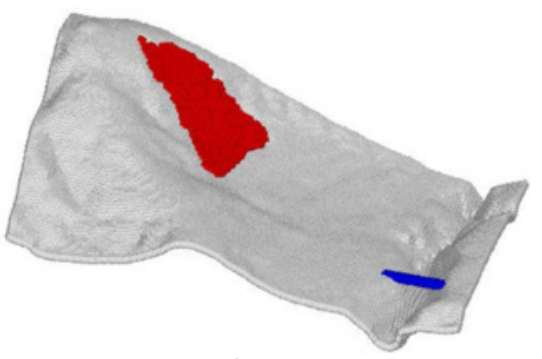

$\mathbf{a}_{\mathrm{t}=0 \mathrm{~s}}$

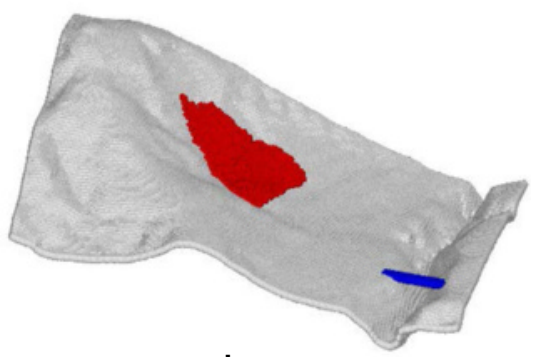

$\mathbf{b}_{\mathrm{t}=15 \mathrm{~s}}$
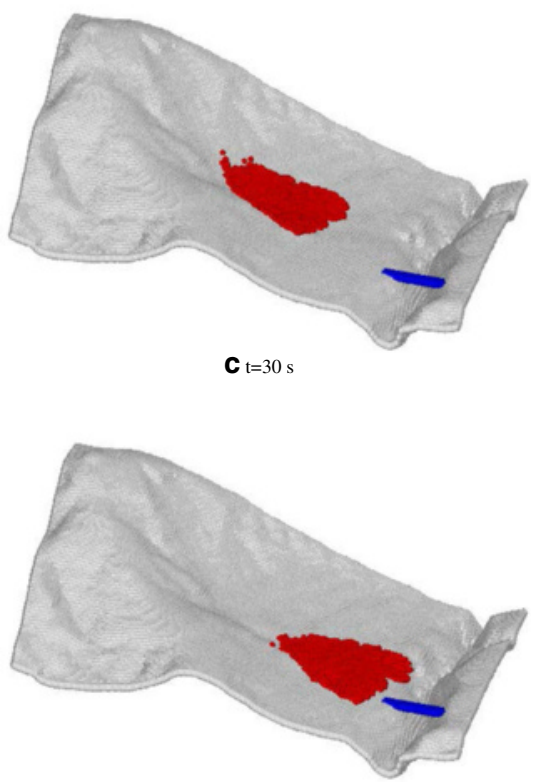

$\mathbf{d}_{\mathrm{t}=45 \mathrm{~s}}$

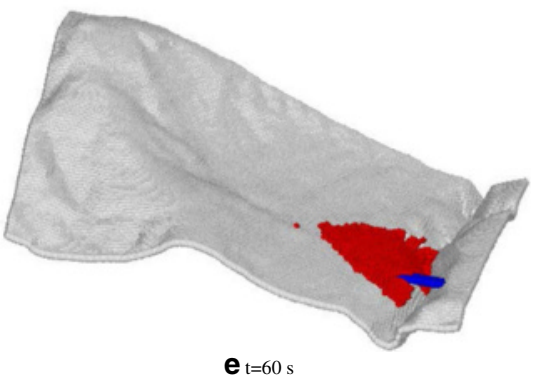

Fig. 11 Simulated propagation of the landslide near Aso Bridge; a $\mathrm{t}=0 \mathrm{~s}, \mathbf{b} \mathrm{t}=15 \mathrm{~s}, \mathbf{c} \mathrm{t}=30 \mathrm{~s}, \mathbf{d} \mathrm{t}=45 \mathrm{~s}$, e $\mathrm{t}=60 \mathrm{~s}$
Table 1 The parameters used in the propagation simulation of the landslide near Aso Bridge

\begin{tabular}{lll}
\hline Density & $\rho\left(\mathrm{kg} / \mathrm{m}^{3}\right)$ & 1975 \\
Yield strength & $\tau_{y}(\mathrm{kPa})$ & 20 \\
Viscosity coefficient & $\eta(\mathrm{Pa} \cdot \mathrm{s})$ & 100 \\
Acceleration of gravity & $g\left(\mathrm{~m} / \mathrm{s}^{2}\right)$ & 9.8 \\
Unit time step & $\Delta t(\mathrm{~s})$ & $2.0 \times 10^{-4}$ \\
Time step & $n$ & $4.0 \times 10^{5}$ \\
\hline
\end{tabular}

slope. Finally the landslide mass reached the Aso Bridge and filled the gorge. To analyze the post-failure behavior of the landslide, the displacement time-history and the velocity time-history of the landslide mass are shown in Fig. 12. The total sliding time was about 50s. The maximum velocity was about $14.1 \mathrm{~m} / \mathrm{s}$, which occurred at about $13.5 \mathrm{~s}$ after failure. The run-out distance of the landslide was about $364.5 \mathrm{~m}$. According to the field investigation, the run-out distance of the landslide was about 395 m, as shown in Fig. 6. Therefore, the numerical results from the SPH model coincided with the actual results.

Based on the SPH modeling, the propagation of the landslide was reproduced. The trajectory, sliding velocity and finally run-out distance were calculated. From the numerical results, it can be observed that the sliding velocity of the landslide was quite large. Therefore, the impact force of the landslide mass was huge. The structures on its trajectory were all damaged including the railway, road and the Aso Bridge.

\section{The landslide in the northeast of the Aso Volcanological Laboratory}

Another landslide triggered by the Kumamoto earthquake is located at $32.888^{\circ} \mathrm{N}, 131.007^{\circ} \mathrm{E}$. the contour map of this landslide is shown in Fig. 13. The Aso

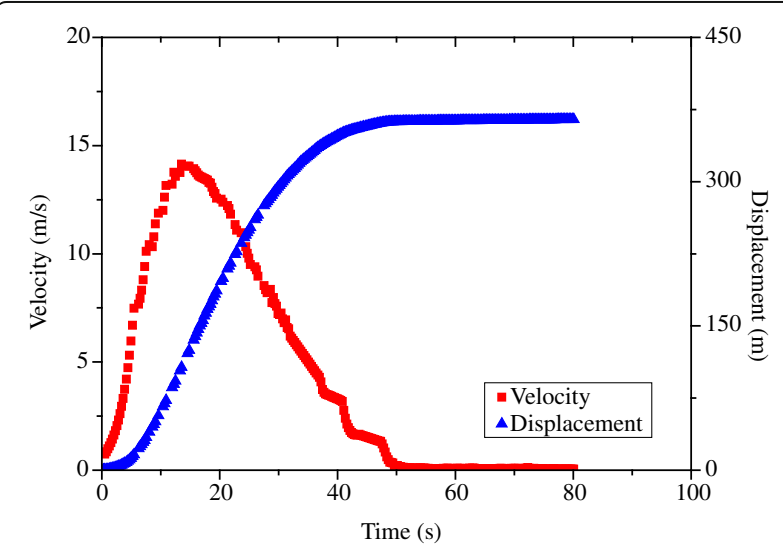

Fig. 12 Displacement time-history and the velocity time-history of the landslide near Aso Bridge 


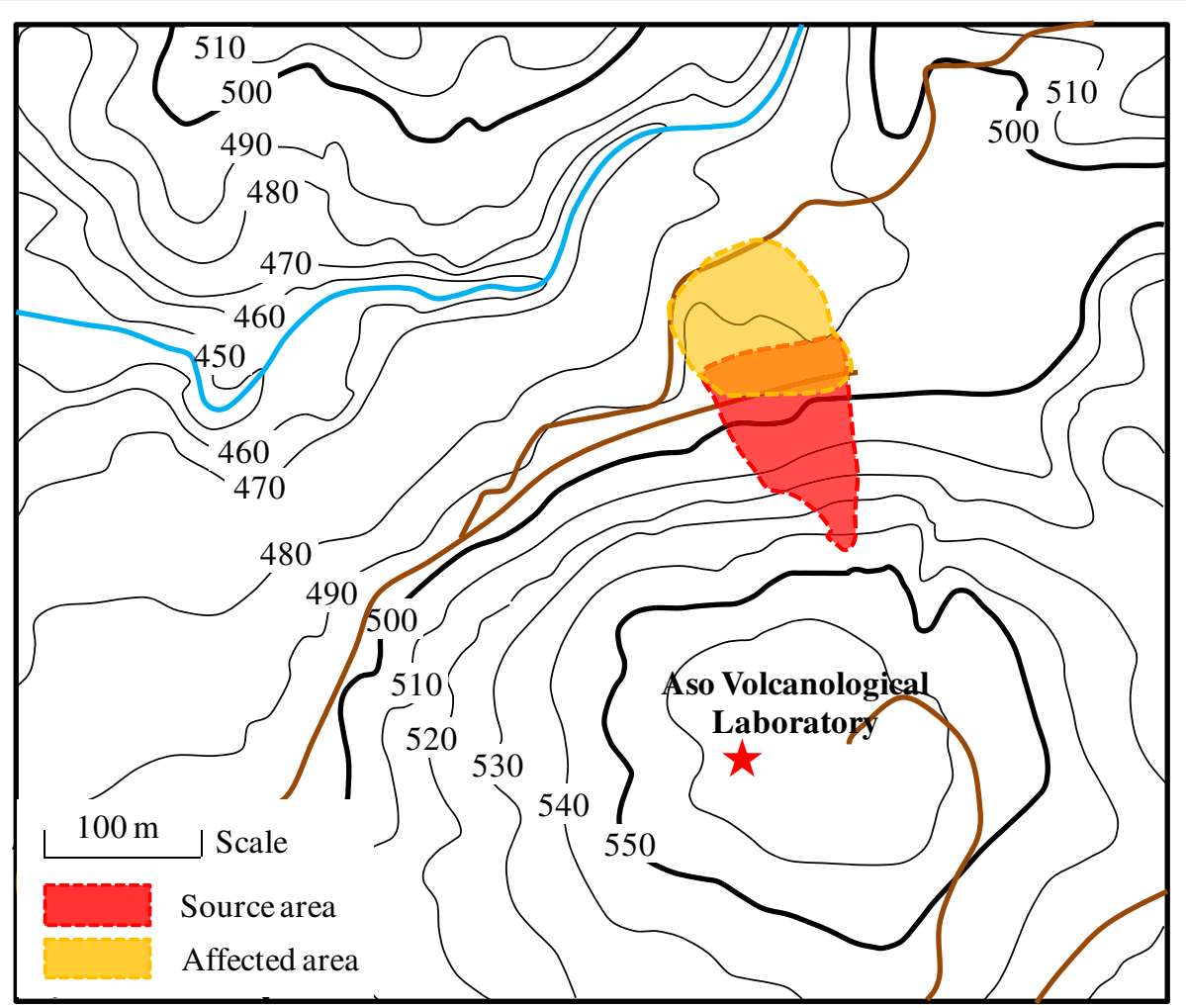

Fig. 13 The contour map of the landslide near the Aso Volcanological Laboratory (Base map is from Geospatial Information Authority of Japan)

Volcanological Laboratory of Kyoto University is located on the top of the slope, about $200 \mathrm{~m}$ to the southwest. Figure 14 is a view from the toe of the landslide, towards the source area, which was taken by an unmanned aerial vehicle (DJI Phantom 3 Advanced). The main scarp, surface of the rupture, right and left flanks, toe of the landslide could be easily identified, which are indicated in the figure. According to the geo-disaster investigation after the earthquake, this was a translation slide which moved along a relatively planar surface of rupture with little rotational movement and backward tilting. The slide direction was $\mathrm{N} 25.0^{\circ} \mathrm{W}$. The dimension of the rupture surface was about $110 \mathrm{~m}$ in length and $90 \mathrm{~m}$ in width. Its area was about $7600 \mathrm{~m}^{2}$. The total volume of

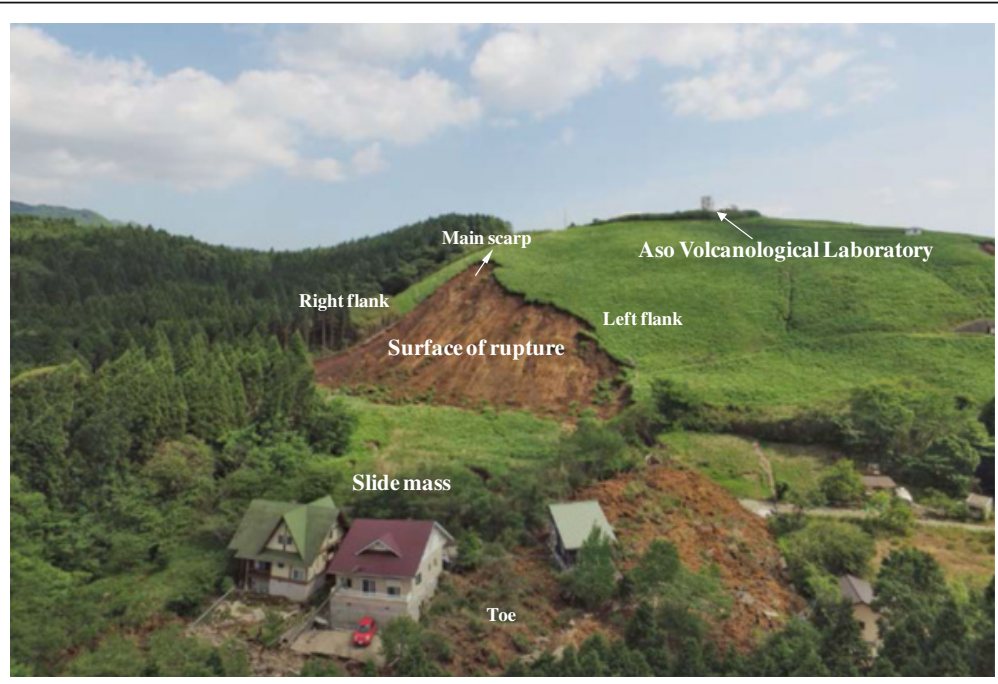

Fig. 14 Aerial view of the landslide near Aso Volcanological Laboratory 


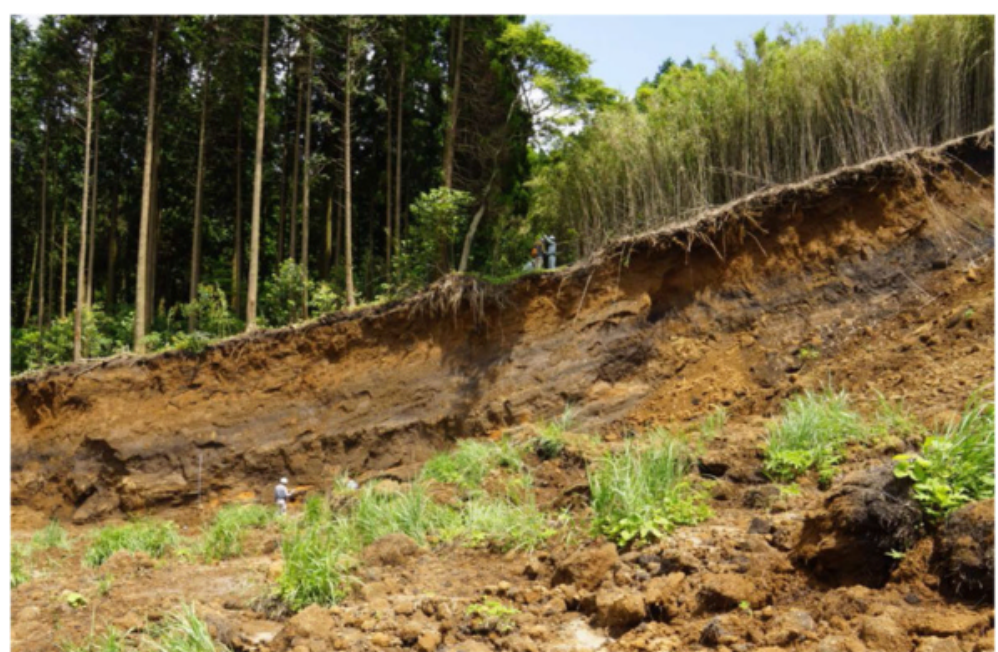

Fig. 15 Soil layers in the right frank of the landslide

the displaced mass was about $5.0 \times 10^{4} \mathrm{~m}^{3}$. The source area of the landslide was gentle (about $23^{\circ}$ ) and the surrounding terrain was also not steep. The elevation difference between the landslide toe and top was only $60 \mathrm{~m}$. The run-out distance of the landslide was about $65 \mathrm{~m}$, therefore the distance-to-length ratio of this landslide was about 0.59. On the landslide mass, the vegetation basically remained intact which indicate the structural integrity of the landslide mass. Figure 15 shows the right flank of the landslide. It can be observed that the average depth of the rupture surface was shallow, about $6.5 \mathrm{~m}$, with a depth-tolength ratio of 0.06 . The soil of the slope was distributed as layers paralleling to the surface of rupture, which was caused by the deposition of volcanic ash from the Aso Volcano nearby.

Though the scale of this landslide was not very large, the damage caused was significant. As shown in Fig. 14, three houses with green, red and white roof were remaining on the displaced mass. During the disaster, they moved together with the failed slope for about $65 \mathrm{~m}$. However, their structures kept almost undamaged and no obvious cracks were found. Except the three surviving houses, several wood-frame houses at the toe of the landslide were completely destroyed, as shown in Fig. 16.

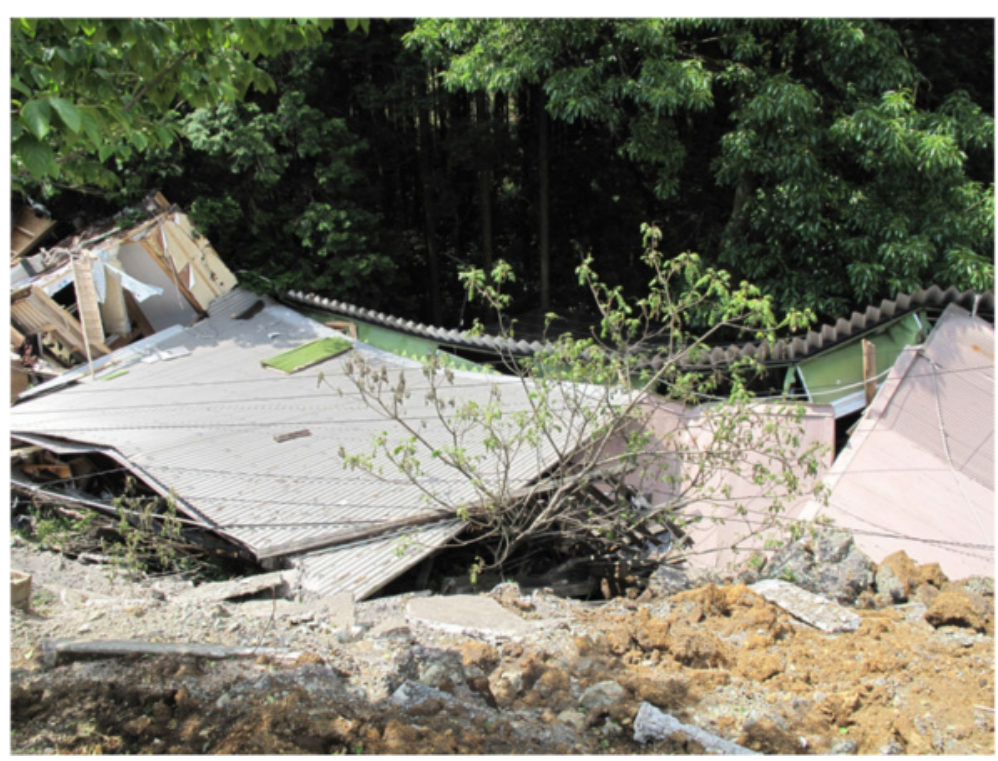

Fig. 16 Collapsed wood-frame houses at the toe of the landslide 


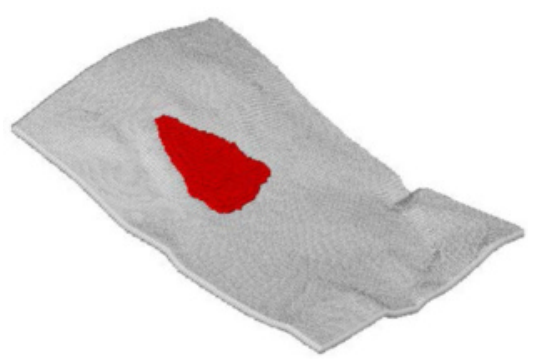

$\mathbf{a}_{\mathrm{t}=0 \mathrm{~s}}$

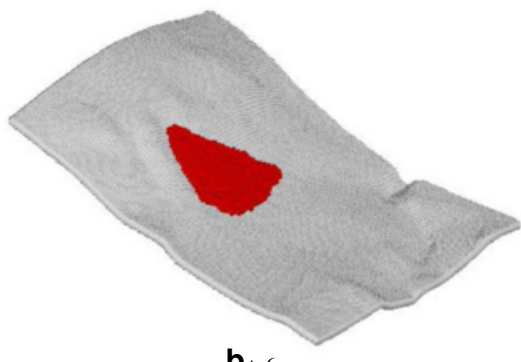

$\mathbf{b}_{\mathrm{t}=6 \mathrm{~s}}$

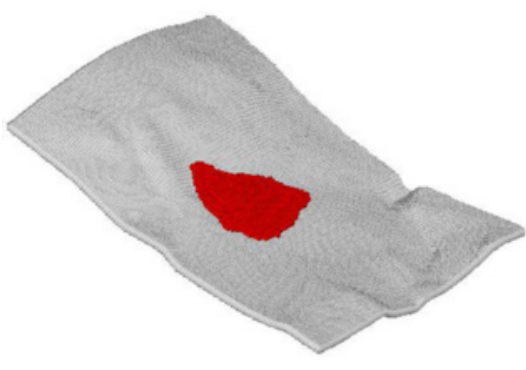

$\mathbf{C}_{\mathrm{t}=12 \mathrm{~s}}$
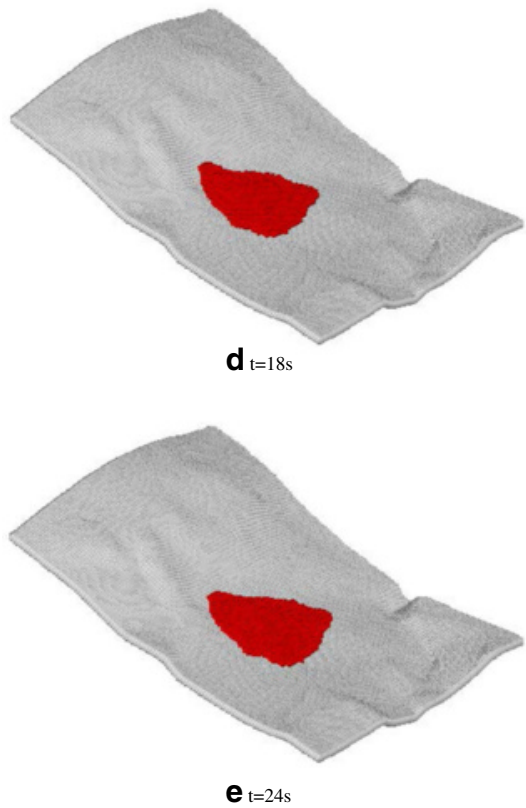

Fig. 17 Simulated propagation of the landslide near Aso Volcanological Laboratory; a $\mathrm{t}=0 \mathrm{~s}, \mathbf{b} \mathrm{t}=6 \mathrm{~s}, \mathbf{c} \mathrm{t}=12 \mathrm{~s}, \mathbf{d} \mathrm{t}=18 \mathrm{~s}$, e $\mathrm{t}=24 \mathrm{~s}$
Compared to the first landslide, the volume of this landslide is small. Therefore, relatively small particles with the diameter of $3 \mathrm{~m}$ were used in this case. As shown in Fig. 17a, the landslide mass was represented by 1851 red particles, and the boundary was discretized into 11,514 white particles. Figure 17 presents the simulated sliding process of the landslide. The soil mass slid down along the slope and piled up at the foot of the slope. Figure 18 shows the displacement and velocity time-histories of the landslide mass. The total sliding time was about $23.0 \mathrm{~s}$. The maximum velocity in the model was about $6.2 \mathrm{~m} / \mathrm{s}$, which occurred at about $7.5 \mathrm{~s}$ after failure. The calculated run-out distance of the landslide was about $70.3 \mathrm{~m}$. According to the field investigation, the run-out distance of the landslide was about $65 \mathrm{~m}$, as shown in Fig. 13. Therefore, the simulated run-out distance was consistent with the measured data.

The location of these two landslides are very close, only about $2180 \mathrm{~m}$ according to Google earth. The soil property are similar, the main composition is the cohesive soil from the Aso volcano nearby. Therefore, the soil strength parameters used in this case was the same as listed in Table 1. Relative to the landslide near Aso Bridge, the slope gradient of the landslide near Volcanological Laboratory is more gentle. Therefore, the sliding velocity of this landslide was smaller, as well as the run-out distance. It shows that the slope gradient and the surrounding terrain influence the post-failure behavior of the landslide mass to some extent.

\section{Conclusion}

The 2016 Kumamoto earthquake triggered a lot of fast landslides in Kyushu Region, and caused serious loss of life and property. Predicting the post-failure behavior of

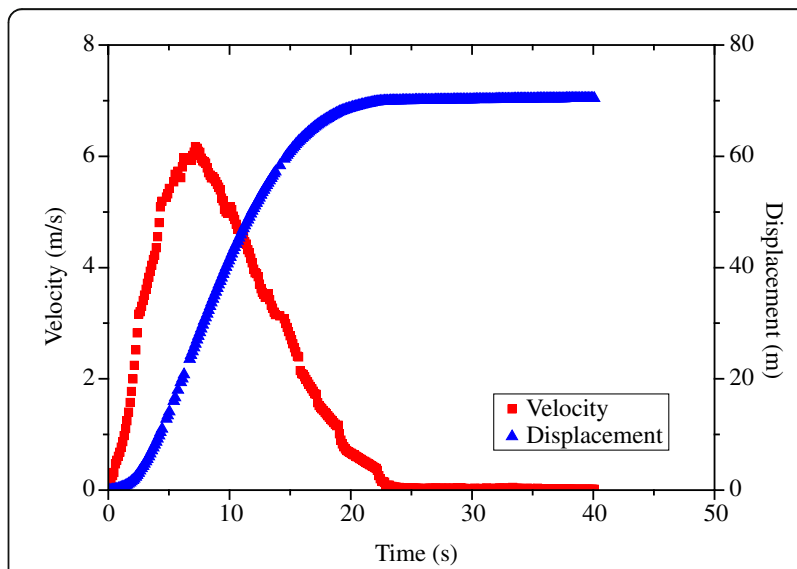

Fig. 18 Displacement time-history and the velocity time-history of the landslide near Aso Volcanological Laboratory 
these landslides is of importance to determine the hazardous areas and estimate the extent of damage.

To analyze the post-behavior of the landslide, a 3D numerical model was presented based on smoothed particle hydrodynamics. A Bingham flow model and the equations of continuity and motion were used to describe the motion of the SPH particles.

Two typical landslides triggered by the Kumamoto earthquake were taken as the case studies. Field investigations were carried out to obtain the landslide features, soil properties and 3D terrain landscapes. The damages caused by these two landslides were described.

The propagation of these two landslides were simulated using the presented SPH model. The moving path of the landslide mass was reproduced. The time history of the velocity and run-out distance were calculated. The simulated run-out distance was consistent with the measured data in the field work, thus verifying the calculation accuracy of the SPH model.

\section{Acknowledgement}

This work was partially supported by a fund for exploratory research from Shimane University (principal researcher: Atsushi Kamei), Open Fund of State Key laboratory of Geohazard Prevention and Geoenvironmental Protection (Chengdu University of Technology) (Grant No. SKLGP2017K005), Open Fund of Hubei Key laboratory of Disaster Prevention and Reduction, China (Three Gorges University) (Grant No. 2016KJZ06) and the National Natural Science Foundation of China (Grant No. 41530639). The authors would like to sincerely thank Mr. Osamu Osaka from Nihonkai Technical Consultants Co., Ltd and Mr. Seiji Sakata from Shimaken Consultant Co., Ltd for their work in field investigation in Kumamoto.

\section{Authors' contributions}

$\mathrm{ZD}, \mathrm{FW}, \mathrm{KS}$ and $\mathrm{Al}$ carried out the field investigation in Kumamoto earthquake zone. ZD conducted the numerical simulations and $\mathrm{YH}$ provided technical support at the stage of SPH modeling. ZD drafted the manuscript and all authors read and approved the manuscript.

\section{Competing interests}

The authors declare that they have no competing interests.

\section{Author details}

'Department of Geoscience, Shimane University, Matsue, Shimane 690-8504, Japan. ${ }^{2}$ Department of Geotechnical Engineering, College of Civil Engineering, Tongji University, Shanghai 200092, China. ${ }^{3}$ Hubei Key Laboratory of Disaster Prevention and Reduction, China Three Gorges University, Yichang 443002, China.

Received: 21 September 2016 Accepted: 16 November 2016 Published online: 29 November 2016

\section{References}

Andersen, S., and L. Andersen. 2010. Modelling of landslides with the materialpoint method. Computational Geosciences 14(1): 137-147.

Blanc, T., M. Pastor, M. Sanchez, V. Drempetic, and B. Haddad. 2011. Depth integrated modelling of fast landslide propagation. European Journal of Environmental and Civil Engineering 15(SI): 51-72.

Cascini, L., S. Cuomo, M. Pastor, G. Sorbino, and L. Piciullo. 2014. SPH run-out modelling of channelised landslides of the flow type. Geomorphology 214: 502-513.

Chen, H., and C.F. Lee. 2002. Runout analysis of slurry flows with Bingham model. Journal of Geotechnical and Geoenvironmental Engineering 128(12): 1032-1042.

Collins, B.D., and N. Sitar. 2011. Stability of steep slopes in cemented sands. Journal of Geotechnical and Geoenvironmental Engineering 137(1): 43-51.
Dai, Z., Y. Huang, H. Cheng, and Q. Xu. 2014. 3D numerical modeling using smoothed particle hydrodynamics of flow-like landslide propagation triggered by the 2008 Wenchuan earthquake. Engineering Geology 180: 21-33.

Dominguez, J.M., A.J.C. Crespo, M. Gomez-Gesteira, and J.C. Marongiu. 2011. Neighbour lists in smoothed particle hydrodynamics. International Journal for Numerical Methods in Fluids 67(12): 2026-2042.

Gingold, R.A., and J.J. Monaghan. 1977. Smoothed Particle Hydrodynamics: theory and application to non-spherial stars. Monthly Notices of the Royal Astronomical 181: 375-389.

Haddad, B., M. Pastor, D. Palacios, and E. Munoz-Salinas. 2010. A SPH depth integrated model for Popocatepetl 2001 lahar (Mexico): sensitivity analysis and runout simulation. Engineering Geology 114(3-4): 312-329.

Hassani, R., L.R. Ionescu, and T. Lachand-Robert. 2005. Shape optimization and supremal minimization approaches in landslides modeling. Applied Mathematics and Optimization 52(3): 349-364.

Hayashi, Y., M. Mizota, A. Suzuki, Y. Kitazono, and H. Harada. 2005. Chemical treatment of soft soils containing $\mathrm{Cr}(\mathrm{VI})$ with different clay minerals. In Stabilisation/Solidification treatment and remediation: Proceedings of the International Conference on Stabilisation/Solidification Treatment and Remediation, 57. Cambridge, UK: CRC Press.

Huang, Y., Z. Dai, W. Zhang, and Z. Chen. 2011. Visual simulation of landslide fluidized movement based on smoothed particle hydrodynamics. Natural Hazards 59(3): 1225-1238.

Huang, Y., W. Zhang, Q. Xu, P. Xie, and L. Hao. 2012. Run-out analysis of flow-like landslides triggered by the Ms 8.02008 Wenchuan earthquake using smoothed particle hydrodynamics. Landslides 9(2): 275-283.

Lin, C.H., and M.L. Lin. 2015. Evolution of the large landslide induced by Typhoon Morakot: a case study in the Butangbunasi River, southern Taiwan using the discrete element method. Engineering Geology 197: 172-187.

LO, E.Y.M., and S. Shao. 2002. Simulation of near-shore solitary wave mechanics by an incompressible SPH method. Applied Ocean Research 24(5): 275-286.

Lucy, L.B. 1977. A numerical approach to the testing of the fission hypothesis. Astronomical Journal 82(12): 1013-1024.

McDougall, S., and O. Hungr. 2004. A model for the analysis of rapid landslide motion across three-dimensional terrain. Canadian Geotechnical Journal 41(6): 1084-1097.

Monaghan, J.J. 1994. Simulating free surface flows with SPH. Journal of Computational Physics 110(2): 399-406.

Monaghan, J.J., and R.A. Gingold. 1983. Shock simulation by the particle method SPH. Journal of Computational Physics 52: 374-389.

Monaghan, J.J., and J.C. Lattanzio. 1985. A refined particle method for astrophysical problems. Astronomy and Astrophysics 149(1): 135-143.

Morris, J.P., P.J. Fox, and Y. Zhu. 1997. Modeling low reynolds number incompressible flows using SPH. Journal of Computational Physics 136: 214-226.

Okumura, K. 2016. Earthquake Geology of the April 14 and 16, 2016 Kumamoto Earthquakes, The Kumamoto Earthquake Investigation: a preliminary report, 19-24.

Pastor, M., B. Haddad, G. Sorbino, S. Cuomo, and V. Drempetic. 2008. A depth-integrated, coupled SPH model for flow-like landslides and related phenomena. International Journal for Numerical and Analytical Methods in Geomechanics 33(2): 143-172.

Pastor, M., I. Herreros, J.A.F. Merodo, P. Mira, B. Haddad, M. Quecedo, E. Gonzalez, C. Alvarez-Cedron, and V. Drempetic. 2009. Modelling of fast catastrophic landslides and impulse waves induced by them in fjords, lakes and reservoirs. Engineering Geology 109(1-2): 124-134.

Pastor, M., B. Blanc, B. Haddad, S. Petrone, M.E. Sanchez Morles, V. Drempetic, D. Issler, G.B. Crosta, L. Cascini, G. Sorbino, and S. Cuomo. 2014. Application of a SPH depthintegrated model to landslide run-out analysis. Landslides 11(5): 793-812.

Remaître, A. 2006. Morphologie et dynamique des laves torrentielles: Applications aux torrents des Terres Noires du bassin de Barcelonnette (Alpes du Sud), Ph.D. thesis.

Ulusay, R., O. Aydan, and R. Kilic. 2007. Geotechnical assessment of the 2005 Kuzulu landslide (Turkey). Engineering Geology 89(1-2): 112-128.

Verlet, L. 1967. Computer "Experiments" on classical fluids. I. Thermodynamical properties of Lennard-Jones molecules. Physical Review 159(1): 98-103.

Wang, F., Q. Cheng, L. Highland, M. Miyajima, H. Wang, and C. Yan. 2009. Preliminary investigation of some large landslides triggered by the 2008 Wenchuan earthquake, Sichuan Province, China. Landslides 6(1): 47-54.

Xu, W.J., Q. Xu, and Y.J. Wang. 2013. The mechanism of high-speed motion and damming of the Tangjiashan landslide. Engineering Geology 157: 8-20.

Yin, Y., F. Wang, and P. Sun. 2009. Landslide hazards triggered by the 2008 Wenchuan earthquake, Sichuan, China. Landslides 6(2): 139-152.

Zhang, YJ, Wang, Q, Xu, G, Chen, JX, Zhao, L, Zheng, Z, Han, and Yu P. 2015a. DDA validation of the mobility of earthquake-induced landslides. Engineering Geology 194: 38-51. 
Zhang, X, K, Krabbenhoft, D, Sheng, W, Li. 2015b. Numerical simulation of a flow-like landslide using the particle finite element method. Computational Mechanics 55(1): 167-177.

Zhou, X.P., and H. Cheng. 2013. Analysis of stability of three-dimensional slopes using the rigorous limit equilibrium method. Engineering Geology 160: 21-33.

\section{Submit your manuscript to a SpringerOpen ${ }^{\circ}$ journal and benefit from:}

- Convenient online submission

- Rigorous peer review

- Immediate publication on acceptance

- Open access: articles freely available online

- High visibility within the field

Retaining the copyright to your article

Submit your next manuscript at $>$ springeropen.com 